\title{
Emotional Impact Survey of Dental Patients with Tooth Loss in Unsyiah Dental Hospital, Banda Aceh, Indonesia
}

\author{
${ }^{1}$ Liana Rahmayani, ${ }^{2}$ Cut Fera Novita, ${ }^{3}$ Wirdatul Ahya
}

\begin{abstract}
Introduction: Loss of teeth is a condition where one or several teeth are lost from the socket. Loss of one or several anterior teeth can cause esthetic disruption, loss of confidence, concerns about appearance, and lost function of the teeth, thereby greatly affecting an individual's mind and activity. The loss of some or all of the teeth has many impacts, one of which is the emotional impact. Emotional impact is a feeling or assessment reaction that is derived from the nervous system in response to stimuli from the outside or inside due to loss of teeth, which is known through the categories affected, avoidance, depression, irritability, embarrassment, and feeling old.
\end{abstract}

Aim: This study aimed to describe the emotional impact of tooth loss in patients at Unsyiah Dental Hospital, Banda Aceh, Indonesia.

Materials and methods: This research was a descriptive, cross-sectional design. Sampling was done by random sampling method, which included 100 respondents.

Results: The results showed that the emotional impact that can be caused by tooth loss in patients at Unsyiah Dental Hospital in the period from January to March is as follows: $50 \%$ classified as mild, $39 \%$ moderate, and $11 \%$ severe. Emotional effects of losing a tooth are as follows: $49 \%$ disturbed category, $7 \%$ avoidance, $7 \%$ depression, $4 \%$ offended, $30 \%$ embarrassed, and $54 \%$ feeling old.

Conclusion: The emotional impact of tooth loss in patients at our dental hospital is classified as mild to severe, of which a mild emotional impact was found often.

Clinical significance: Tooth loss is one of the common problems that often occurred at the dental clinic, and loss of teeth function can greatly affect an individual's mind and activity.

Keywords: Depression, Embarrassed, Emotional effect, Tooth loss.

How to cite this article: Rahmayani L, Novita CF, Ahya W. Emotional Impact Survey of Dental Patients with Tooth Loss

\footnotetext{
${ }^{1}$ Department of Prosthodontics, Faculty of Dentistry, Syiah Kuala University, Banda Aceh, Indonesia

${ }^{2}$ Department of Public Health, Faculty of Dentistry, Syiah Kuala University, Banda Aceh, Indonesia

${ }^{3}$ Dental Education Program, Faculty of Dentistry, Syiah Kuala University, Banda Aceh, Indonesia

Corresponding Author: Liana Rahmayani, Department of Prosthodontic, Faculty of Dentistry, Syiah Kuala University Banda Aceh, Indonesia, Phone: +06517555183, e-mail: liana. rahmayani@unsyiah.ac.id
}

in Unsyiah Dental Hospital, Banda Aceh, Indonesia. World J Dent 2018;9(1):24-28.

Source of support: Nil

Conflict of interest: None

\section{INTRODUCTION}

Teeth are the most important part of the oral cavity primarily because the functions of the teeth in chewing, esthetics, and speech cannot be replaced. ${ }^{1}$ Tooth loss is a global public health issue that is common among adults. ${ }^{2}$ According to the Basic Health Research and Development, Ministry of Health, Republic of Indonesia, ${ }^{3}$ the national prevalence of oral and dental problems is $25.9 \%$, with a total of 14 provinces exhibiting the maximum prevalence of dental and oral health problems.

Tooth loss is one of the common problems at the dental clinic. ${ }^{4}$ Tooth loss is a condition where one or a few teeth are lost from the socket, which can be caused by caries, periodontal disease, orthodontic treatment, and cystic lesions. ${ }^{5-7}$ Tooth loss of one or some of anterior teeth can cause esthetic disruption, loss of confidence, concerns about appearance, and loss of function of the teeth, thereby, greatly affecting an individual's mind and activity ${ }^{8-10}$ Imperfect appearance can affect an individual's self-esteem, thus leading to work productivity decline, and ultimately, having an impact on the quality-of-life. Based on these effects, it can be said that dental health and emotions related to it are the results of the interactions between the physical, mental, and social factors. ${ }^{10}$

Loss of teeth for longer lifecycles can affect the quality-of-life of an individual, which can also cause a state of depression due to disturbances in speech, esthetics, chewing, and lead to feelings of inferiority because an important part of the body has disappeared. Loss of few teeth or all of the teeth has an impact on the emotional, systemic, and functional aspects. ${ }^{11,12}$ Emotional impact is a complex psychological experience of an individual's state of mind as the result of the interaction of the external and internal environments. ${ }^{13}$ Emotional impact due to tooth loss includes a reduced sense of self-trust, disruption of activities, and changes in appearance. ${ }^{12}$

A research by Shah et $\mathrm{al}^{14}$ showed that $58 \%$ of patients in India who lost all their teeth had difficulty in accepting 
the loss of teeth. Similarly, Okoje et $\mathrm{al}^{15}$ showed that in the Nigerian society, the patients reported that the emotional effects caused by tooth loss are as follows: $12.9 \%$ felt sad, $6.4 \%$ were depressed, $14 \%$ felt loss of some major part of their body, $2.3 \%$ had a feeling of aging, and $7.6 \%$ of individuals felt they were not cared for. The results obtained from a study conducted on the people of India and Nigeria can be applicable to other people also, especially in the city of Banda Aceh.

The Faculty of Dentistry, Syiah Kuala University (Unsyiah), is one of the teaching hospitals belonging to Unsyiah, located in Banda Aceh, with the goal of providing health care of teeth and mouth to the community comprising people of different social status, who have varied backgrounds and treatment needs. Treatment services provided include filling cavities, tooth extraction, denture treatment, and various other dental treatments. To the best of our knowledge, research on the description of the emotional impacts due to tooth loss has not been widely investigated. Therefore, we decided to examine this aspect in patients at the Unsyiah Dental Hospital in order to add to the information and knowledge regarding the emotional impact of tooth loss.

\section{MATERIALS AND METHODS}

A letter to the Unsyiah Dental Hospital was prepared, and then informed consent forms and questionnaires were prepared. The experiment was conducted at the Unsyiah Dental Hospital. Before filling out the research questionnaires, respondents were given explanations about the purpose of the study. Then, the researchers gave informed consent forms or forms of approval to the respondents who were willing to participate in this research. Subsequently, the respondents were asked to complete the questionnaire within 15 minutes. After the respondents finished the task, the research questionnaire was returned to the researchers. Researchers used the questionnaires to collect data sheets. The questionnaire provided contained questions that were based on the concepts and theories extracted according to the literature review and information review. Questionnaires have been structured in such a way for respondents to easily provide answers to instructions.

In this study, a questionnaire was used where respondents were asked to only choose one answer for each question and they had to cross $(X)$ on the column provided by the researcher. The questionnaire consists of three parts:

1. Part $\mathrm{A}$ was the part of the questionnaire containing demographic data, and the demographic data, such as respondent's identity included respondent code, name, gender, age, occupation, address, and lastly education.
2. Part B was the part of the questionnaire containing details on how to fill out the questionnaire.

3. Part $\mathrm{C}$ was the part of the questionnaire containing 12 questions about tooth loss used to measure the emotional impact.

After the questionnaire was filled, the data were processed by editing or checking the identity of the respondent, the completeness of data, and the contents of the instrument for data collection. The respondent had already signed the consent form. The next stage was the coding with numbers or codes to facilitate data processing. From the questionnaire, the identity and answers obtained from the respondents were examined, and the researchers gave the answer code in the questionnaire. The questionnaires in this study were made by the researchers themselves; if the respondents chose the answer "Yes", it was given a score of 1 and if the respondents chose the answer "No", it was given a score of 0 . After the coding phase has been completed, the next researcher has performed data transfer steps that have been coded in sequence been coded sequentially, from the first respondent to the last respondent entered into the table in accordance with the subvariables studied then examined the stage of tabulation and grouping answers by categories that have been assigned to each subvariable.

\section{RESULTS}

A total of 100 respondents were examined in this study. Distribution of respondents by age, gender, and region of tooth loss is shown in Table 1.

Table 1 summarizes that out of 100 respondents with missing teeth, 27 (27\%) were between the ages 46 and 55 years, while $7(7 \%)$ were between the ages 26 and 35 years.

Table 2 summarizes that of the 100 respondents, there were 44 male (44\%) and 56 female (56\%) patients with missing teeth, who had visited the Unsyiah Dental Hospital in the period from January to March 2016.

Table 1: Distribution of respondents by age

\begin{tabular}{ll}
\hline Age (years) & Amount (\%) \\
\hline $17-25$ & $18(18)$ \\
$26-35$ & $7(7)$ \\
$36-45$ & $22(22)$ \\
$46-55$ & $27(27)$ \\
$56-60$ & $26(26)$ \\
\hline Total & $100(100)$ \\
\hline
\end{tabular}

Table 2: Distribution of respondents by gender

\begin{tabular}{ll}
\hline Gender & Amount (\%) \\
\hline Male & $44(44)$ \\
Female & $56(56)$ \\
\hline Total & $100(100)$ \\
\hline
\end{tabular}


Table 3: Distribution of respondents by region's loss of teeth

\begin{tabular}{ll}
\hline Tooth loss region & Amount (\%) \\
\hline Anterior region & $7(7)$ \\
Posterior region & $63(63)$ \\
Anterior and posterior region & $30(30)$ \\
\hline Total & $100(100)$ \\
\hline
\end{tabular}

Table 5: Description of the emotional impact in losing teeth by patients at Unsyiah Dental Hospital

\begin{tabular}{|c|c|c|c|c|}
\hline \multirow[b]{2}{*}{$\begin{array}{l}\text { Emotional } \\
\text { impact }\end{array}$} & \multicolumn{3}{|c|}{ Tooth loss region } & \multirow[b]{2}{*}{ Total (\%) } \\
\hline & Anterior (\%) & Posterior (\%) & $\begin{array}{l}\text { Anterior and } \\
\text { posterior (\%) }\end{array}$ & \\
\hline Mild & $2(2)$ & $41(41)$ & $7(7)$ & $50(50)$ \\
\hline Medium & $4(4)$ & $19(19)$ & $16(16)$ & $39(39)$ \\
\hline Severe & $1(1)$ & $3(3)$ & $7(7)$ & $11(11)$ \\
\hline Total & $7(7)$ & $63(63)$ & $30(30)$ & $100(100)$ \\
\hline
\end{tabular}

Table 3 summarizes that out of the 100 respondents with missing teeth, $63(63 \%)$ lost their teeth in the posterior region, $30(30 \%)$ lost their teeth in the anterior and posterior regions, and $7(7 \%)$ lost their teeth in the anterior region.

Table 4 summarizes that out of the 100 respondents, $49(49 \%)$ were affected emotionally and scored against the category disrupted, $7(7 \%)$ scored for the category avoided, 7 (7\%) scored for the category depressed, 4 (4\%) scored for the category offended, $30(30 \%)$ scored for the category embarrassment, and $54(54 \%)$ scored for the category feeling old.

Table 5 summarizes that out of the 100 respondents with missing teeth, $50(50 \%)$ experienced mild emotional impact, 39 (39\%) experienced medium emotional impact, and $11(11 \%)$ experienced severe emotional impact.

\section{DISCUSSION}

This study was conducted on patients with missing teeth in the Dental Hospital, University of Syiah Kuala. This study aimed to describe the emotional impact on patients who have lost their teeth. The patient's emotional impact in missing teeth is a condition that is an expression of complex emotions due to the experience from individual mind as the interaction of the internal and external environment. $^{13}$

From Table 2, $44(44 \%)$ respondents with missing teeth were male and $56(56 \%)$ were female. These results were consistent with the study done by Fabiola, ${ }^{16}$ who concluded that male patients are less concerned about losing their teeth and are less likely to visit a dentist than female patients. Hence, we conclude that women are more concerned than men about tooth loss and look for a treatment to replace the tooth. This is because women are more concerned about esthetics.

From Table 1, $27(27 \%)$ were between the ages 46 and 55 years, while $7(7 \%)$ were between the ages 26 and
Table 4: Frequency distribution of the emotional impact due to loss of teeth

\begin{tabular}{llll}
\hline Category & Have impact (\%) & No impact (\%) & Total (\%) \\
\hline Disturbed & $49(49)$ & $51(51)$ & $100(100)$ \\
Avoid & $7(7)$ & $93(93)$ & $100(100)$ \\
Depression & $7(7)$ & $93(93)$ & $100(100)$ \\
Offended & $4(4)$ & $96(96)$ & $100(100)$ \\
Embarrassed & $30(30)$ & $70(70)$ & $100(100)$ \\
Feeling old & $54(54)$ & $46(46)$ & $100(100)$ \\
\hline
\end{tabular}

35 years. Some studies suggest that age has been associated with a tooth loss. ${ }^{17}$ Prevalence of tooth loss will increase with age. Tooth loss is increasing in middle age of 40 years and rapidly rises in the age group of 75 years, while people above 75 years lose all their teeth. This is because the longer the teeth are present in the mouth, the greater the risk of tooth decay, which ultimately causes loss of teeth. ${ }^{8,18} \mathrm{~A}$ large number of missing teeth will certainly increase the demand or desire for denture treatment to restore the function of the tooth lost. The pretension for making the denture is typically associated with physiological needs; it is not being the main thing for the patient anymore. However, the desire for the treatment with the use of dentures will increase, which is mostly related to the patient's desire to look better when smiling and not based on the physiological needs. ${ }^{19}$ This is in accordance with the above theory; the results of this study showed that most respondents are in the age group of 45 to 55 years, as many as 27 people ( $27 \%$ ) with an only one difference $(1 \%)$ of the 56 to 60 year age group as many as 26 people $(26 \%)$.

From Table 3, out of the 100 respondents with missing teeth, $63(63 \%)$ lost their teeth in the posterior region, 30 $(30 \%)$ lost their teeth in the anterior and posterior regions, and $7(7 \%)$ lost their teeth in the anterior region. There is early loss of posterior teeth than anterior teeth because the morphology of the posterior teeth has a deep fissure with a sharp inclination on the occlusal plane, thus simplifying the retention of plaque. ${ }^{20}$ In addition, the posterior teeth have a masticatory function that is more widely used than that of the anterior teeth. ${ }^{8}$ These results are consistent with Anne studies in 2004, according to which the teeth in the posterior region are lost more than those of the anterior region. ${ }^{12}$

Table 4 summarizes that out of the 100 respondents, $49(49 \%)$ were affected emotionally by the category disrupted. Loss of teeth was the most frequent cause of the malfunctioning of mastication, especially in the posterior region. ${ }^{8,21}$ The few remaining teeth will decrease the efficiency of food mastication that will affect nutritional status. These results are consistent with Anne's study (2004) of tooth loss that may interfere with chewing certain foods. Loss of teeth in the anterior region can 
disrupt the esthetics that affects the psychological aspects of an individual; ${ }^{18}$ it makes an individual avoid smiling/ laughing in public. ${ }^{12}$

From Table 4, 7 (7\%) respondents were affected by the category avoidance. In their research, Suresh and Sharma ${ }^{22}$ reported that individuals who lost their teeth tend to be embarrassed to smile in front of other people. Everyone wants to be accepted and to interact comfortably in a social group, but this can be interrupted due to loss of teeth, which interferes with appearance and speech. This is in accordance with the research by Shah et $\mathrm{al}^{14}$ which highlighted that in India as many as $11 \%$ of respondents with tooth loss, who were researched, avoided interaction with others.

Based on the categories of depression as shown in Table 4, 7 people (7\%) from the 100 respondents experienced an emotional impact. Loss of teeth for longer lifecycles may affect an individual's quality-of-life that can also cause depression due to disturbances in speech, esthetics, and chewing. Feelings of inferiority become prominent because an important part of the individual's body has been missing, thereby, affecting appearance and speech negatively. It can reduce the level of confidence that leads to people withdrawing from the community. ${ }^{14,23}$ This is consistent with the research by Okoje et $\mathrm{al}^{15}$ in Nigeria, in which as many as $6.4 \%$ of the respondents surveyed felt depressed over the loss of teeth. Feelings of regret and limited the social activity were also displayed.

As shown in Table 4, based on the category offended, $4(4 \%)$ out of the 100 respondents experienced an emotional impact. Based on the Putri's study in 2004, assessing the social dimension in quality of life, most respondents $(79.5 \%)$ never feel irritable because one of the problems of the oral cavity is tooth loss. ${ }^{24}$

As shown in Table 4, based on the category embarrassed, as many as 30 (30\%) of the 100 respondents experienced an emotional impact. The changes due to loss of teeth make people feel very disturbed, experience loss of confidence, aware of the appearance of tooth loss, and assume something that this is not ought to be discussed so that patients remain secretive. ${ }^{23,25}$ This is consistent with the research by Shah et al, ${ }^{14}$ which showed that as many as 38\% respondents surveyed felt a loss of confidence after experiencing tooth loss.

As shown in Table 4, based on the category of the old feelings, 54 (54\%) out of the 100 respondents experienced an emotional impact. In the loss of anterior teeth usually show a change of face on the lips and chin that causes the nasolabial groove deepens, and the face becomes older. $^{25,26}$ This is consistent with the research by Shah et $\mathrm{al}^{14}{ }^{14}$ which showed that as many as $22 \%$ of the 100 respondents felt elderly for losing teeth.
Table 5 summarizes that out of the 100 respondents with missing teeth, 50 (50\%) experienced mild emotional impact, 39 (39\%) experienced medium emotional impact, and 11 (11\%) experienced severe emotional impact. The majority of the frequency distribution in this study is the posterior region. Posterior teeth have a masticatory function and, hence, are more widely used than the anterior teeth. The most common emotional impact that can be caused by tooth loss is not being comfortable in chewing; this is in accordance with the research by Anne in 2010, More than half of respondents feel constrained in choosing food, avoiding outside activities, while establishing relationships were not a common problem due to tooth loss. ${ }^{12}$

Limitations of this study were that the majority of research participants lost their tooth in the posterior region, meaning that the emotional impact was different. Functionally, tooth loss may result in decreased chewing efficiency, migration and rotation of teeth, and temporomandibular joint disorders, as well as difficulty in speaking. Emotionally, tooth loss can cause feelings of sadness and loss of confidence due to the loss of esthetic function. ${ }^{9,27}$

\section{CONCLUSION}

The emotional impacts that were caused by tooth loss in patients at the Dental Hospital of Banda Aceh in the period of January to March 2016 are classified as mild to severe, in which a mild emotional impact was found often. As many as 50 people were in the mild category $(50 \%)$, while $39(39 \%)$ were in the medium category, and 11 people $(11 \%)$ were in the severe category. The percentage of emotional impact was $49 \%$ as disturbed, $7 \%$ as avoidance, $7 \%$ as depression, $4 \%$ as offended, $30 \%$ as embarrassment, and 54\% as feeling old. Although the emotional impact was mostly found in the mild category, tooth loss is one of the common problems that often occur at the dental clinic and loss of teeth function can greatly affect an individual's mind and activity.

\section{REFERENCES}

1. Ramadan. Various dental and oral health. Jakarta: Bukune; 2010. p. 86.

2. Beltran-Aguilar BL, Canto MT, Dye BA, Gooch BF, Griffin SO, Hyman J, Jaramillo F, Kingman A, Noejack-Raymer R, Selwitz RH, et al. Surveillance for dental caries, dental sealants, tooth retention, edentulism, and enamel fluorosisUnited States, 1988-1994 and 1999-2002. MMWR Surveill Summ 2005 Aug;54(3):1-44.

3. The Ministry of Health of the Indonesian Republic. Basic health research. Jakarta: Department of Health; 2013. p. 10.

4. Abouelkomsan AM, Butt AM, Dall AQ. Removable partial dentures: Patient satisfaction with associated demographic 
and biomechanical factors. Pak Oral Dent J 2012 Dec;32(3): 564-568.

5. Khalifa N, Allen PF, Abu-bakr NH, Abdel-Rahman ME. Factors associated with tooth loss and prosthodontics status among Sudanese adults. J Oral Sci 2012 Oct;54(4): 303-312.

6. Ehikhamenor EE, Oboro HO, Onuora OI, Umanah AU, Chukwumah NM, Aivboraye IA. Types of removable prostheses requested by patients who were presented to the university of Benin teaching hospital dental clinic. J Dent Oral Hyg 2010 Aug;2(2):15-18.

7. Ngangi RS, Mariati WN, Hutagalung BSP. Description of tooth extraction in polyclinics dental hospital Sam Ratulangi University in 2012. Unsrat J 2013; 1(2):1-7.

8. Carr AB, David TB. Mc Cracken's removable partial prosthodontics. 12th ed. St. Louis (MO): Elsevier Mosby; 2011. p. 5.

9. Davis DM, Fiske J, Scott B, Radford DR. The emotional effects of tooth loss: a preliminary quantitative study. Br Dent $\mathrm{J} 2000$ May;188(9):503-506.

10. Silviana AW, Mariati NW. Perceptions about care denture on Urban village community Maasing Tumuning district of Manado City. J e-GiGi (eG) 2013;1:1-5.

11. Jones JA, Orner MB, Spiro A 3rd, Kressin NR. Tooth loss and dentures: patients' perspectives. Int Dent J 2003 Nov;53(5 Suppl):327-334.

12. McMillan AS, Wong MC. Emotional effect of tooth loss in community-dwelling elderly people in Hong Kong. Int J Prosthodont 2004 Mar-Apr;17(2):172-176.

13. Sarwono. Introduction to general psychology. Jakarta: PT Rajagrfindo Persada; 2009. pp. 124-125.

14. Shah RJ, Diwan FJ, Diwan MJ, Chauhan VJ, Agrawal HS, Patel GC. A study of the emotional effects of tooth loss in an edentulous Gujarati population and its association with depression. J Indian Prosthodont Soc 2015 Jul-Sep;15(3): 237-243.

15. Okoje VN, Dosumu OO, Alonge TO, Onyeaso C. Tooth loss: are the patients prepared? Niger J Clin Pract 2012 AprJun;15(2):172-175.
16. Fabiola I. Factors associated with public figures visits to the clinic of the faculty of dentistry, university of Gajah Mada. Ind Dent Assoc J 2006;56:37-38.

17. Shamdol Z, Ismail NM, Hamzah NT, Ismail AR. Prevalence and associated factor of edentulism among elderly Muslims in Kota Bharu, Kelantan, Malaysia. J Indian Med Assoc 2008 Dec;40(4):143-148.

18. Kida IA. Examining tooth loss, oral impacts on daily performances and satisfaction with chewing ability. Bergen: Thesis of University of Bergen; 2007. pp. 5-17.

19. Murshid P. Factors affecting patients in selection type denture in Kodingareng. Essay. Makassar: Faculty of Dentistry, University of Hasanuddin; 2011. p. 2.

20. Sakaguchi R, Powers J. Craig's restorative dental material. 13th ed. St. Louis (MO): CV. Mosby Company; 2011.

21. Inukai M, John MT, Igarashi $Y$, Baba K. Association between perceives chewing ability and oral health related quality of life in partially dentate patient. Health Qual Life Outcomes 2010 Oct; $8: 118$.

22. Suresh S, Sharma S. A clinical survey to determine the awareness and preference of needs of a complete denture among complete edentulous patient. J Int Oral Health 2010 Oct;2(3):65-70.

23. Agtini MD. Percentage of users prosthesis in Indonesia. Med Health Res Dev 2010 Jun;20(2):50-58.

24. Putri AI. Losing influence on the quality of life dental some seniors in Makassar. Essay. Makassar: Faculty of Dentistry, University of Hasanuddin; 2014. pp. 37-38.

25. Zarb GA. Prosthodontic treatment for edentulous patient complete dentures and implant-supported prostheses. 12th ed. India: Elsevier; 2004. pp. 1-21.

26. Leung KC, Pow EH. Oral rehabilitation with removable partial dentures in advanced tooth loss situation. Hong Kong Dent J 2009;6(1):39-45.

27. Hugo FN, Hilgert JB, de Sousa ML, da Silva DD, Pucca GA Jr. Correlate of partial tooth loss and edentulism in Brazilian elderly. Community Dent Oral Epidemiol 2007 Jun;35(3): 224-232. 